\title{
Lung cancer in never-smokers: a case-control study in a radon-prone area (Galicia, Spain)
}

\author{
María Torres-Durán ${ }^{1}$, Alberto Ruano-Ravina ${ }^{2,3}$, Isaura Parente-Lamelas ${ }^{4}$, \\ Virginia Leiro-Fernández ${ }^{1}$, José Abal-Arca ${ }^{4}$, Carmen Montero-Martínez ${ }^{5}$, \\ Carolina Pena-Álvarez ${ }^{6}$, Francisco Javier González-Barcala7, Olalla Castro-Añón ${ }^{8}$, \\ Antonio Golpe-Gómez ${ }^{7}$, Cristina Martínez ${ }^{9}$, María José Mejuto-Martí10, \\ Alberto Fernández-Villar ${ }^{1}$ and Juan Miguel Barros-Dios ${ }^{2,3,11}$
}

\begin{abstract}
Affiliations: 'Service of Pneumology. University Hospital Complex of Vigo, Vigo, Spain. ${ }^{2}$ Dept of Preventive Medicine and Public Health, University of Santiago de Compostela. Santiago de Compostela, Spain. ${ }^{3} \mathrm{CIBER}$ de Epidemiología y Salud Pública, CIBERESP, Spain. ${ }^{4}$ Service of Pneumology, Ourense Hospital Complex, Spain. ${ }^{5}$ Service of Pneumology, University Hospital Complex of A Coruña, A Coruña, Spain. 'Service of Oncology, Pontevedra Hospital Complex, Pontevedra, Spain. ${ }^{7}$ Service of Pneumology, Santiago de Compostela University Clinic Hospital, Santiago de Compostela, Spain. ${ }^{8}$ Service of Pneumology, Hospital Lucus Augusti, Lugo, Spain. ${ }^{9}$ National Institute of Silicosis, University Hospital of Asturias, Oviedo. Spain. ${ }^{10}$ Service of Pneumology, Hospital Arquitecto Marcide, Ferrol, Spain. ${ }^{11}$ Service of Preventive Medicine. University Hospital Complex of Santiago de Compostela, A Coruña Spain.
\end{abstract}

Correspondence: Alberto Ruano-Ravina, Dept of Preventive Medicine and Public Health, School of Medicine, C/San Francisco s/n, University of Santiago de Compostela, 15782. Santiago de Compostela, Spain.

E-mail: alberto.ruanodusc.es

ABSTRACT The aim of the study was to assess the effect of residential radon exposure on the risk of lung cancer in never-smokers and to ascertain if environmental tobacco smoke modifies the effect of residential radon.

We designed a multicentre hospital-based case-control study in a radon-prone area (Galicia, Spain). All participants were never-smokers. Cases had an anatomopathologically confirmed primary lung cancer and controls were recruited from individuals undergoing minor, non-oncological surgery. Residential radon was measured using alpha track detectors.

We included 521 individuals, 192 cases and 329 controls, $21 \%$ were males. We observed an odds ratio of $2.42\left(95 \%\right.$ CI 1.45-4.06) for individuals exposed to $\geqslant 200 \mathrm{~Bq} \cdot \mathrm{m}^{-3}$ compared with those exposed to $<100 \mathrm{~Bq} \cdot \mathrm{m}^{-3}$. Environmental tobacco smoke exposure at home increased lung cancer risk in individuals with radon exposure $>200 \mathrm{~Bq} \cdot \mathrm{m}^{-3}$. Individuals exposed to environmental tobacco smoke and to radon concentrations $>200 \mathrm{~Bq} \cdot \mathrm{m}^{-3}$ had higher lung cancer risk than those exposed to lower radon concentrations and exposed to environmental tobacco smoke.

Residential radon increases lung cancer risk in never-smokers. An association between residential radon exposure and environmental tobacco smoke on the risk of lung cancer might exist.

@ERSpublications

Residential radon exposure increases risk of lung cancer in never-smokers, ETS exposure may raise radon effect http://ow.ly/xRVte

For editorial comments see page 850 .

Earn CME accreditation by answering questions about this article. You will find these at erj.ersjournals.com/misc/ cmeinfo.xhtml

Received: Jan 262014 | Accepted after revision: June 042014 | First published online: July 172014

Support statement: This paper was funded by a competitive research grant from the Xunta de Galicia: 10CSA208057PR "Risk factors of lung cancer in never smokers: a multicenter case-control study in the Northwest of Spain."

Conflict of interest: None declared

Copyright @ERS 2014 


\section{Introduction}

Lung cancer is currently the leading cause of cancer death worldwide. Tobacco consumption is the most important risk factor for lung cancer; however, between $15-25 \%$ of all lung cancer cases occur in neversmokers [1]. Recent research suggests that lung cancer in never-smokers could be a different disease than lung cancer in smokers, since different molecular pathways are present in never-smokers' lung cancer $[2,3]$. These patients also have higher survival, a different age of onset and have mainly adenocarcinomas $[4,5]$.

Residential radon exposure is the second risk factor of lung cancer after tobacco consumption and the first risk factor for never-smokers [6]. Residential radon was declared a human carcinogen in 1987 by the World Health Organization (WHO) and in 1988 by the US Environmental Protection Agency (EPA). The US EPA considers an action level of $148 \mathrm{~Bq} \cdot \mathrm{m}^{-3}$ whereas WHO has recently lowered the action level to $100 \mathrm{~Bq} \cdot \mathrm{m}^{-3}[6,7]$.

Two pooling studies, which included case-control studies performed in Europe and North America, found a linear relationship between residential radon exposure and lung cancer risk $[8,9]$. The European pooling included 884 never-smoker cases and 5418 never-smoker controls. In the latter subgroup, there is an excess of relative risk of $10.6 \%$ per $100 \mathrm{~Bq} \cdot \mathrm{m}^{-3}$ was observed, slightly higher than the risk observed for ex- and current-smokers. In the American pooling study there was no difference between ever- and never-smokers for risk of lung cancer. In both groups the excess of relative risk was 10\%. Very few case-control studies [10-12] have been performed that have included never-smokers and the results are conflicting. A recent systematic review [13] suggests a possible relationship between residential radon exposure and lung cancer in neversmokers and it seems that there is a dose-response pattern.

A problem that appears when assessing the relationship between residential radon and lung cancer is the low variability in radon concentrations, which makes it difficult to assess possible dose-response patterns. Galicia, the study area, has been characterised as a radon-prone region by previous studies [14, 15]. Furthermore, Galician population has low mobility compared with other populations, which facilitates the attribution of lung cancer to radon exposure [15].

Environmental tobacco smoke (ETS) is a risk factor for lung cancer. In 1992, it was recognised as a human carcinogen by the US EPA [16]. Only one study has suggested that there is a synergism between residential radon and ETS [12]. This synergism could be explained because radon and tobacco smoke may have a different carcinogenic mechanism, with different mutational patterns for each risk factor [17].

The aim of the present study is to assess the effect of residential radon exposure on the risk of lung cancer in never-smokers and to ascertain if ETS exposure can modify the effect of residential radon.

\section{Material and methods \\ Design and setting}

We designed a multicentre hospital-based case-control study in the Northwest of Spain (Galicia and Asturias). All public hospitals in Galicia $(n=7)$ and the most important hospital in Asturias (Hospital Central de Asturias) took part. $95 \%$ of the patients in the study population area had universal healthcare coverage. Lung cancer diagnosis and staging was only performed in the hospitals included in the study. The study area comprised of both urban and rural areas, and $\sim 50 \%$ of the population lived in detached houses in the countryside.

Cases and controls were recruited between January 2011 and June 2013. All participants were neversmokers. A never-smoker was defined as: 1) an individual reporting $<100$ cigarettes in a lifetime or 2) had not smoked for 6 months. To be included, cases had to have an anatomopathologically confirmed lung cancer. Cases and controls had to be aged $>30$ years with no upper age limit. Individuals with previous cancers were excluded. Cases were identified by pneumologists assigned to the lung cancer rapid-diagnosis pathway at each hospital.

Controls were recruited from ambulatory individuals undergoing minor, non-oncological surgery. The following hospitals provided controls: Santiago de Compostela, Ourense, Vigo and Lugo; the first three hospitals cover geographic areas that have slightly higher residential radon concentrations than the Lugo area. Controls were selected using a frequency sampling on age and sex distribution regarding cases in order to assure comparability between cases and controls on these two variables.

The study protocol was approved by the Galician Committee of Research Ethics (reference 2010/295) and all participants signed written consent for participation.

\section{Data collection and radon measurement}

All participants were personally interviewed at hospital by trained researchers using a questionnaire. They were asked about different aspects of their lifestyle, with special emphasis on ETS exposure, leisure time 
exposures, diet, and alcohol consumption. Participants provided a biological sample of $3 \mathrm{~mL}$ of blood in order to analyse genetic polymorphisms and its relation with lung cancer onset.

We retrieved detailed information on ETS exposure from all participants. We asked them if they had or had not lived with a smoker during the last 20 years. In an affirmative case we asked about the relationship, the number of years of cohabitation, and the number of cigarettes per day smoked by the cohabitant. We collected information of up to four smoking cohabitants. We also collected information for ETS exposure during childhood or at work. Since the most relevant exposure for lung cancer appearance is ETS at home and due to changes regarding smoking at work (enforced by law) in the recent years, we only considered ETS exposure at home in our analysis.

The interviewer gave the participants a radon detector to take home and positioning instructions, which included a picture on how to correctly position the detector in the home. Participants also received a prepaid envelope to send back the detector to the coordinating centre once the measurement period had finished. The detector was of the alpha-track type (CR-39; Radosys Inc., Budapest, Hungary). The detector was placed in the participant's bedroom, at a height between 60 and $180 \mathrm{~cm}$ from the floor, away from doors, windows, heating and electrical devices. The minimum period of exposure was 3 months. 1 week after the detector was given to the patient, a researcher phoned the participant. This was undertaken in order to ensure the correct positioning of the device and to answer any doubts or questions the participant may have had. Once the exposure period finished, another phone call was made to inform the participant that he/she should send back the radon detector. Specific instructions for sealing the device, once it was retired from use, were given. The devices were read at the Galician Radon Laboratory (Santiago de Compostela, Spain), which has been certified by the University of Cantabria, with excellent results in intercomparison exercises [18]. We also performed periodical quality controls with blanks and sending detectors to other radon laboratories for intercomparison purposes. Radon measurements were seasonally adjusted in order to consider radon variability throughout the year. We sent to the participants the results of the radon measurements, with specific recommendations depending on the radon concentration observed at each home.

\section{Statistical analysis}

We performed a bivariate descriptive analysis to determine the distribution of the study variables according to the case or control status. Following this analysis, we used a multiple logistic regression where the dependent variable was the case or controls status and the independent variable residential radon exposure broken down in four categories $\left(\leqslant 100,101-147,148-199\right.$ and $\left.\geqslant 200 \mathrm{~Bq} \cdot \mathrm{m}^{-3}\right)$. As adjustment variables, we introduced in the model age (continuous), sex, and ETS exposure defined as having lived with a smoker or not for $>20$ years. We repeated the same analysis but only including females and also including only individuals who had lived $\geqslant 20$ years in the same dwelling.

To assess if ETS exposure at home, defined as the time living with a smoker modified the risk of lung cancer due to residential radon, we created a variable with six categories through syntaxes. This variable combined two categories for residential radon $\left(<200\right.$ and $\left.\geqslant 200 \mathrm{~Bq} \cdot \mathrm{m}^{-3}\right)$ and three for years living with a smoker $(0$, $1-35$ and $\geqslant 36$ years). The results were adjusted by age and sex. All the results are expressed as odds ratios with 95\% confidence intervals. The software used for the analysis was IBM SPSS v20 (IBM, Armonk, NY, USA).

\section{Results}

521 individuals, 192 cases and 329 controls were included. The participation rate was high, $>90 \%$ of cases and $75 \%$ of controls accepted to took part in the study. 15 cases ( $7.8 \%$ of the total included) were recruited in Asturias. The sex distribution was very similar among cases and controls and also the age distribution. $21 \%$ were males and the median age was 70 years for cases and controls. Education levels were similar between both groups and the percentage of individuals who had worked in risk occupations for lung cancer did not differ between cases and controls. More cases than controls lived in rural areas, but there were no statistically significant differences between radon concentrations in each of the habitats, though residential radon was slightly higher in rural areas. Radon exposure was considerably higher among cases compared with controls. $48 \%$ of cases had residential radon exposure $>200 \mathrm{~Bq} \cdot \mathrm{m}^{-3}$ compared with $29.4 \%$ for the controls. The returning rate of radon detectors was 177 (92.2\%) out of 192 for cases and $272(82.6 \%)$ out of 329 for controls. The median number of years living in the measured home was 30 years for cases and 36 years for controls. The percentage of controls living with smokers in adulthood was $45.1 \%$ compared with $42.2 \%$ in cases $(\mathrm{p}=0.051)$. Regarding histological types, $77.5 \%$ had adenocarcinoma, followed by $10.0 \%$ with squamous cell carcinoma. The sample characteristics appear on table 1. 
TABLE 1 Patients in the study characteristics

\begin{tabular}{|c|c|c|}
\hline Variable & Cases & Controls \\
\hline Patients n & 192 & 329 \\
\hline Age years median (range)/25-75 percentile & $70(34-87) / 61-77$ & $70(43-90) / 63.5-79$ \\
\hline \multicolumn{3}{|l|}{ Sex } \\
\hline Female & $153(79.7)$ & $259(78.7)$ \\
\hline Male & 39 (20.3) & $70(21.3)$ \\
\hline \multicolumn{3}{|l|}{ Education } \\
\hline No formal studies & $49(26.1)$ & $51(15.5)$ \\
\hline Primary school & $114(60.6)$ & $246(74.7)$ \\
\hline High school & $13(6.9)$ & $19(5.8)$ \\
\hline University degree & $12(6.4)$ & $13(4.0)$ \\
\hline \multicolumn{3}{|l|}{ Have worked in risk occupations for lung cancer ${ }^{\#}$} \\
\hline No & $163(87.2)$ & $281(87.3)$ \\
\hline Yes & $24(12.8)$ & $41(12.7)$ \\
\hline \multicolumn{3}{|l|}{ Participant's habitat } \\
\hline Urban & $77(40.5)$ & $74(22.6)$ \\
\hline Rural & $113(59.5)$ & $254(77.4)$ \\
\hline \multicolumn{3}{|l|}{ Residential radon exposure $\mathrm{Bq} \cdot \mathrm{m}^{-3}$} \\
\hline$\leqslant 100$ & $36(20.3)$ & $73(26.9)$ \\
\hline $101-147$ & $24(13.6)$ & $61(22.4)$ \\
\hline $148-199$ & $32(18.1)$ & $58(21.3)$ \\
\hline$\geqslant 200$ & $85(48.0)$ & $80(29.4)$ \\
\hline \multicolumn{3}{|l|}{ Years living in the measured dwelling } \\
\hline median (25-75 percentiles) & $30(17-44)$ & $36(20-52)$ \\
\hline \multicolumn{3}{|l|}{ Exposure to ETS at home in the last 20 years } \\
\hline Yes & $81(42.2)$ & $148(45.1)$ \\
\hline No & $111(57.8)$ & $180(54.9)$ \\
\hline \multicolumn{3}{|l|}{ Histological types } \\
\hline Adenocarcinoma & $148(77.5)$ & \\
\hline Squamous cell carcinoma & $19(10.0)$ & \\
\hline Small cell carcinoma & $12(6.3)$ & \\
\hline Large cell carcinoma & $6(3.1)$ & \\
\hline Other histological types & $6(3.1)$ & \\
\hline
\end{tabular}

Data are presented as $\mathrm{n}(\%)$ unless otherwise stated. ETS: environmental tobacco smoke. \#: following the classification proposed by Ahrens And MerLetTI [19].

Regarding the effect of residential radon on lung cancer risk in never-smokers, we observed an OR of 2.42 (95\% CI 1.45-4.06) for individuals exposed to concentrations $>200 \mathrm{~Bq} \cdot \mathrm{m}^{-3}$, taking those individuals exposed to $<100 \mathrm{~Bq} \cdot \mathrm{m}^{-3}$ as a reference. The other exposure categories did not show a significant effect. When we restricted the analysis to only females, we observed an OR 2.84 (95\% CI 1.58-5.09) for those exposed $>200 \mathrm{~Bq} \cdot \mathrm{m}^{-3}$. Finally, for individuals who had lived for $\geqslant 20$ years in the same dwelling, we found $1.83 \mathrm{OR}$ (95\% CI 1.01-3.30) when patients were exposed to $\geqslant 200 \mathrm{~Bq} \cdot \mathrm{m}^{-3}$ compared with those exposed to $<100 \mathrm{~Bq} \cdot \mathrm{m}^{-3}$. The effect of radon exposure on lung cancer risk can be observed in table 2 .

The effect modification, due to exposure to ETS, on the relationship between residential radon and lung cancer is shown in table 3. The risk of lung cancer does not increase with the number of years living with a smoker for individuals exposed to residential radon $<200 \mathrm{~Bq} \cdot \mathrm{m}^{-3}$. Nevertheless, for individuals exposed to $>200 \mathrm{~Bq} \cdot \mathrm{m}^{-3}$ the risk of lung cancer is higher for all categories of ETS exposure when compared with their counterparts exposed to radon levels $<200 \mathrm{~Bq} \cdot \mathrm{m}^{-3}$. Individuals exposed to $>200 \mathrm{~Bq} \cdot \mathrm{m}^{-3}$ and who have not lived with a smoker show a risk of 1.99 (95\% CI 1.16-3.41) and this risk changes to 2.75 (95\% CI 1.44-5.25) for those who have lived 1-35 years with a smoker. The last category has a nonsignificant OR of 0.63 , although there were only seven cases and 20 controls in it.

\section{Discussion}

The results of the present study show that residential radon increases the risk of lung cancer in never-smokers when they are exposed to indoor levels $>200 \mathrm{~Bq} \cdot \mathrm{m}^{-3}$. The risk is more than two-fold when compared with those participants exposed to levels $<100 \mathrm{~Bq} \cdot \mathrm{m}^{-3}$. The risk is similar for females and for individuals having 
TABLE 2 Residential radon exposure and risk for lung cancer

Radon exposure $\mathrm{Bq} \cdot \mathrm{m}^{-3}$

\begin{tabular}{|c|c|c|c|c|}
\hline & $\leqslant 100$ & $101-147$ & $148-199$ & $\geqslant 200$ \\
\hline \multicolumn{5}{|l|}{ Patients } \\
\hline Cases & 36 (20.3) & 24 (13.5) & 32 (32.8) & $85(48)$ \\
\hline Controls & 73 (26.8) & $61(22.4)$ & 58 (21.3) & $80(29.4)$ \\
\hline OR $(95 \% \mathrm{CI})^{\#}$ & $1^{\S}$ & $0.84(0.45-1.56)$ & $1.14(0.63-2.06)$ & $2.33(1.40-3.89)$ \\
\hline OR $(95 \% \mathrm{CI})^{\top}$ & $1^{\S}$ & $0.80(0.43-1.50)$ & $1.16(0.64-2.11)$ & $2.42(1.45-4.06)$ \\
\hline \multicolumn{5}{|l|}{ Females } \\
\hline Cases & $29(20.7 \%)$ & 20 (14.3\%) & $24(17.1)$ & $67(47.8)$ \\
\hline Controls & $60(28.3 \%)$ & $46(21.7 \%)$ & $51(24.01)$ & 55 (25.9) \\
\hline OR $\left(95 \% \mathrm{Cl}^{+}\right.$ & $1^{\S}$ & $0.87(0.43-1.75)$ & $1.00(0.52-1.95)$ & $2.84(1.58-5.09)$ \\
\hline \multicolumn{5}{|c|}{$\begin{array}{l}\text { Patients at same } \\
\text { dwelling } \geqslant 20 \text { years }\end{array}$} \\
\hline Cases & $30(24.6)$ & 15 (12.3) & 22 (18.0) & $55(45.1)$ \\
\hline Controls & 57 (28.8) & 37 (18.7) & 37 (18.7) & 67 (33.8) \\
\hline OR $(95 \% \mathrm{Cl})^{\top}$ & $1^{\S}$ & $0.76(0.36-1.61)$ & $1.18(0.59-2.36)$ & $1.83(1.01-3.30)$ \\
\hline
\end{tabular}

Data are presented as $\mathrm{n}(\%)$ unless otherwise stated. ${ }^{*}$ : adjusted for sex and age; ${ }^{\text {}}$ : adjusted for sex, age and environmental tobacco-smoke exposure at home; ${ }^{+}$: adjusted for age and environmental tobacco-smoke exposure at home; ${ }^{\S}$ : no confidence interval as reference category.

lived $\geqslant 20$ years in the same dwelling. Our study is the first to suggest a possible association between residential radon exposure and ETS on the risk of lung cancer.

The present study provides important insights into the health effects of radon exposure in never-smokers, since very few case-control studies have been performed in never-smokers. We observed that the risk becomes significant when levels of radon are $>200 \mathrm{~Bq} \cdot \mathrm{m}^{-3}$; however, the action level as recommended by US EPA is $148 \mathrm{~Bq} \cdot \mathrm{m}^{-3}$ and WHO recently recommended the action level as $100 \mathrm{~Bq} \cdot \mathrm{m}^{-3}[6,7]$. The US EPA and WHO recommendations are based on studies that mainly involved ever-smokers [8,9]. There is an interaction between radon and smoking on the risk of lung cancer, additive or submultiplicative $[8,15,20]$, therefore, the residential radon concentrations necessary to promote lung cancer in ever-smokers should be lower than in never-smokers. The present results confirm this hypothesis; where a significant risk of lung cancer appears only at high concentrations of residential radon $\left(>200 \mathrm{~Bq} \cdot \mathrm{m}^{-3}\right)$. This holds true when analysing joint exposure to ETS and indoor radon. In the current study it was decided to use 100, 148 and $200 \mathrm{~Bq} \cdot \mathrm{m}^{-3}$ as the cut-off points for radon exposure. $100 \mathrm{~Bq} \cdot \mathrm{m}^{-3}$ had to be used as the first category because few individuals were exposed to radon concentrations $<50 \mathrm{~Bq} \cdot \mathrm{m}^{-3}(\mathrm{n}=26)$. However, this first radon level cut-off point is higher than those used in other studies [8,11, 12, 21-23]. The second cut-off point corresponded to the US EPA action level $\left(148 \mathrm{~Bq} \cdot \mathrm{m}^{-3}\right)$, and the final cut-off point $\left(200 \mathrm{~Bq} \cdot \mathrm{m}^{-3}\right)$ is the recommended indoor radon concentration for new houses in the European Union [24].

Available studies on radon and lung cancer in never-smokers show quite similar results. However, most of them were not designed to assess the risk of lung cancer in never-smokers and only present the results as a subanalysis of the main research $[8,9,21,23,25,26$, ]. Studies that exclusively involved never-smokers or had a high sample size of never-smokers in the overall sample, observed a linear increase in excess of the relative risk (ERR) with exposure to residential radon of $0.106(95 \% \mathrm{CI}-0.09-0.42)$ per $100 \mathrm{~Bq} \cdot \mathrm{m}^{-3}$ in the European pooling study [8] and an ERR of 0.28 (95\% CI -0.05-1.05) in the study by LAGARDE et al. [12]. The two most important studies performed in never-smokers are the European pooling study [8] and the study by LAGARDE et al. [12]. Both studies have shown a dose-response effect for radon and lung cancer in never-smokers. The European pooling study shows a statistical significant effect from $100 \mathrm{~Bq} \cdot \mathrm{m}^{-3}$ (OR 1.23 , 95\% CI 1.02-1.48) and the risk increases with radon exposure. The study by LAGARDE et al. [12] shows a significant effect at $140 \mathrm{~Bq} \cdot \mathrm{m}^{-3}$ (OR 1.4, 95\% CI 1.0-2.1). These results show that the risk for lung cancer might be evident at $<200 \mathrm{~Bq} \cdot \mathrm{m}^{-3}$ for never-smokers. A recent systematic review published by our group [13], concluded that it seems to be a dose-response relationship between residential radon and lung cancer in never-smokers. Nevertheless, the results obtained by the different case-control studies mainly depend on the study setting, with those investigations performed in radon-prone areas tending to obtain significant risks and those in areas with low-dose residential radon showing no effect [11]. 
TABLE 3 Environmental tobacco-smoke exposure, residential radon and risk of lung cancer

Radon $^{\#} \mathrm{~Bq} \cdot \mathrm{m}^{-3} \quad$ Living with smokers in the same dwelling ${ }^{\text {T }}$ years

\begin{tabular}{|c|c|c|c|c|c|c|c|c|c|c|c|c|}
\hline & \multicolumn{4}{|c|}{0} & \multicolumn{4}{|c|}{$1-35$} & \multicolumn{4}{|c|}{$\geqslant 36$} \\
\hline & Total & Cases & Controls & $\begin{array}{c}\text { OR } \\
(95 \% \mathrm{Cl})\end{array}$ & Total & Cases & Controls & $\begin{array}{c}\text { OR } \\
(95 \% \mathrm{Cl})\end{array}$ & Total & Cases & Controls & $\begin{array}{c}\text { OR } \\
(95 \% \mathrm{Cl})\end{array}$ \\
\hline$<200$ & 174 & 64 & 110 & $1^{+}$ & 75 & 21 & 54 & $\begin{array}{c}0.57 \\
(0.31-1.06)\end{array}$ & 36 & 8 & 28 & $\begin{array}{c}0.44 \\
(0.19-1.03)\end{array}$ \\
\hline$\geqslant 200$ & 84 & 44 & 40 & $\begin{array}{c}1.99 \\
(1.16-3.41)\end{array}$ & 53 & 33 & 20 & $\begin{array}{c}2.75 \\
(1.44-5.25)\end{array}$ & 27 & 7 & 20 & $\begin{array}{c}0.63 \\
(0.25-1.56)\end{array}$ \\
\hline
\end{tabular}

The slightly higher risk of lung cancer observed when only females were analysed could be due to several explanations: hormonal factors, higher exposure to passive smoking than males [27], or in fact that Galician females spend more time at home than males, since most of the included females were housewives.

An interesting result is the effect modification observed with ETS exposure and residential radon. For individuals exposed to $>200 \mathrm{~Bq} \cdot \mathrm{m}^{-3}$ the risk of lung cancer increases with the number of years living with a smoker, with the exception of the last category that was composed of individuals who had lived $>35$ years with a smoker. For this category there were only 27 individuals, seven cases and 20 controls and, therefore, this particular result cannot be considered conclusive. ETS and radon are human lung carcinogens [28, 29] and it is biologically plausible an association between both risk factors. Since there is an interaction between radon and active smoking, an interaction between radon and ETS is highly possible. Nevertheless, lung cancer risk entailed by ETS exposure is much lower than that posed by active smoking and, therefore, we would need higher radon concentrations and prolonged periods of ETS exposure to find out if such an association exists. In our case, we divided ETS exposure at home into three categories, taking into account that for active smoking it is the duration of smoking that is more important than the number of cigarettes smoked per day for lung cancer risk [30]. The possibility of a joint effect could also be supported due to the different carcinogenic mechanisms of ETS substances [31,32] and radon exposure, which is largely unknown [17]. It is important to highlight that ETS exposure is very difficult to measure. A latency period for lung cancer induction has not been defined and there is no consensus about the best way to measure (and integrate) the effects of ETS exposure than can come from different sources [33]. Nevertheless, ETS exposure at home is the most relevant exposure for lung cancer.

The present study has been performed in a radon-prone area, which is an important advantage because it allows the assessment of dose-response effect of residential radon. In fact, the high levels of radon in Galicia places the population in a natural experiment [34]. Previous studies [14, 15] have observed that $\sim 10-12 \%$ of Galician dwellings have residential radon levels $>200 \mathrm{~Bq} \cdot \mathrm{m}^{-3}$. In the present study $29.4 \%$ of the controls had residential radon $>200 \mathrm{~Bq} \cdot \mathrm{m}^{-3}$. The difference is probably due to previous studies not including areas of Southern Galicia that have naturally high levels of radon, which we included in the present study. There are two more remarkable advantages. The first advantage was the high rate of radon devices returning from cases and controls, $>90 \%$ for cases and $80 \%$ for controls. This was due to the thorough follow-up with the participants, mainly through phone calls. To our knowledge, these figures are the highest reported in the literature. The second advantage is the high number of years that the participants have lived at the same home. The median number of years in the measured dwelling was 30 years and 36 years for cases and controls, respectively, and a low percentage lived $<20$ years. These results are similar to other studies [15, 35], facilitating an easier attribution of lung cancer to radon exposure in comparison with other settings. Finally, the multicentre nature of our study increases its external validity and has allowed the achievement of a relatively high sample size, considering that lung cancer in never-smokers is a rather infrequent disease.

Our study also has some limitations. We have not been able to separately analyse the effect of residential radon on males, since the frequency of never-smoking males is low, with only $20 \%$ of all cases being male. Other investigation in the same area observed similar results [15], with $23.4 \%$ of males in a large series of never-smoking lung cancer cases. The percentage is also similar (20.7\%) in a study performed in Taiwan, with $>1500$ lung cancer cases [16]. Regarding ETS there is no standardised measurement for this exposure [33] and we have chosen as a proxy for this exposure the years living with a smoker in the same home without considering the number of daily cigarettes per day for each inhabitant. Nevertheless, the 
measurement of ETS is extremely complex, because we should take into account the number of cigarettes smoked in the presence of the participant, the number of days (including or not the days during the weekend) and so on. Recall bias might be present, with cases trying to make a greater effort in remembering past exposures to ETS compared with controls. This information bias could be greater for individuals who have lived for a longer period with a smoker. Our trained interviewers tried to avoid this bias performing standardised interviews. There is a low possibility of a selection bias for the included lung cancer cases and controls. Practically all the population living in the studied area has universal healthcare coverage and, to our knowledge, lung cancer diagnosis is not undertaken outside of the participating hospitals. Since the radon device was given at the time of diagnoses, there is a very low probability of selection bias for cases. Controls were selected at four participating hospitals. Three of these hospitals are placed in areas known to have slightly higher residential radon concentrations and this fact could bias the results towards the null hypothesis (no effect for radon). This has not been the case. When we have analysed the results excluding lung cancer cases from hospitals, with a priori, lower radon concentrations in their catchment area (Asturias, La Coruña, Lugo and Ferrol), the results varied very little (data not shown). These hospitals contributed with 56 cases, accounting for $29 \%$ of all cases.

To conclude, residential radon is a risk factor for lung cancer in never-smokers. The risk is apparent for levels $>200 \mathrm{~Bq} \cdot \mathrm{m}^{-3}$ and is practically the same when we restrict the analysis to females or to individuals who have lived for a minimum of 20 years in the same dwelling. There seems to be a joint effect of residential radon with ETS exposure, with individuals with both exposures having a higher risk of lung cancer. These results support preventive and awareness activities to also be directed to never-smokers, with the objective to reduce their exposure to residential radon. Public health authorities should consider including in their messages the higher risk that is posed by residential radon when ETS is present.

\section{References}

1 Ferlay J, Shin HR, Bray F, et al. Estimates of worldwide burden of cancer in 2008: GLOBOCAN 2008. Int J Cancer 2010; 127: 2893-2917.

2 Sun S, Schiller JH, Gazdar AF. Lung cancer in never smokers - a different disease. Nat Rev Cancer 2007; 7: 778-790.

3 Rudin CM, Avila-Tang E, Harris CC, et al. Lung cancer in never smokers: molecular profiles and therapeutic implications. Clin Cancer Res 2009; 15: 5646-5661.

4 Yano T, Miura N, Takenaka T, et al. Never-smoking nonsmall cell lung cancer as a separate entity: clinicopathologic features and survival. Cancer 2008; 113: 1012-1018.

5 Samet JM, Avila-Tang E, Boffetta P, et al. Lung cancer in never smokers: clinical epidemiology and environmental risk factors. Clin Cancer Res 2009; 15: 5626-5645.

6 US Environmental Protection Agency. A Citizen's Guide to Radon: The Guide to Protecting Yourself and Your Family from Radon. Washington, US Environmental Protection Agency, 2012. Available from: www.epa.gov/ radon/pubs/citguide.html

7 Zeeb H, Shannoun F. WHO Handbook on Indoor Radon: a Public Health Perspective. Geneva, World Health Organization, 2009.

8 Darby S, Hill D, Auvinen A, et al. Radon in homes and risk of lung cancer: collaborative analysis of individual data from 13 European case-control studies. BMJ 2005; 330: 223.

9 Krewski D, Lubin JH, Zielinski JM, et al. Residential radon and risk of lung cancer: a combined analysis of 7 North American case-control studies. Epidemiology 2005; 16: 137-145.

10 Kreuzer M, Heinrich J, Kreienbrock L, et al. Risk factors for lung cancer among nonsmoking women. Int J Cancer 2002; 100: 706-713.

11 Kreuzer M, Gerken M, Kreienbrock L, et al. Lung cancer in lifetime nonsmoking men - results of a case-control study in Germany. Br J Cancer 2001; 84: 134-140.

12 Lagarde F, Axelsson G, Damber L, et al. Residential radon and lung cancer among never-smokers in Sweden. Epidemiology 2001; 12: 396-404.

13 Torres-Durán M, Barros-Dios JM, Fernández-Villar A, et al. Residential radon and lung cancer in never smokers: a systematic review. Cancer Lett 2014; 345: 21-26.

14 Barros-Dios JM, Ruano-Ravina A, Gastelu-Iturri J, et al. Factors underlying residential radon concentration: results from Galicia, Spain. Environ Res 2007; 103: 185-190.

15 Barros-Dios JM, Ruano-Ravina A, Pérez-Ríos M, et al. Residential radon exposure, histologic types, and lung cancer risk. A case-control study in Galicia, Spain. Cancer Epidemiol Biomark Prev 2012; 21: 951-958.

16 Environmental Protection Agency. Respiratory Health Effects of Passive Smoking: Lung Cancer and Other Disorders. EPA/600/6-90/006F. Washington, US Environmental Protection Agency, 1992.

17 Ruano-Ravina A, Faraldo-Valles MJ, Barros-Dios JM. Is there a specific mutation of p53 gene due to radon exposure? A systematic review. Int J Radiat Biol 2009; 85: 614-621.

18 Gutierrez-Villanueva JL, Sainz-Fernández C, Fuente-Merino I, et al. Intercomparison exercise on external gamma dose rate under field conditions at the laboratory of natural radiation (Saelices el Chico, Spain). Radiat Prot Dosimetry 2013; 155: 459-466.

19 Ahrens W, Merletti F A standard tool for the analysis of occupational lung cancer in epidemiologic studies, Int J Occup Environ Health 1998; 4: 236-240.

20 National Research Council. Effects of Exposures to Radon: BEIR VI. Washington, National Academy Press, 1999.

21 Pershagen G, Akerblom G, Axelson O, et al. Residential radon exposure and lung cancer in Sweden. N Engl J Med 1994; 330: 159-164.

22 Alavanja MC, Brownson RC, Lubin $\mathrm{JH}$, et al. Residential radon exposure and lung cancer among nonsmoking women. J Natl Cancer Inst 1994; 86: 1829-1837. 

Jersey women. Cancer Res 1990; 50: 6520-6524.

24 Ripa Di Meana C. Commission Recommendation of 21 February 1990 on the Protection of the Public Against Indoor Exposure to Radon (90/143/Euratom). Brussels, The Commission for the European Communities, 1990. Available from: http://ec.europa.eu/energy/nuclear/radioprotection/doc/legislation/90143_en.pdf

25 Field RW, Steck DJ, Smith BJ, et al. The Iowa radon lung cancer study - phase I: Residential radon gas exposure and lung cancer. Sci Total Environ 2001; 272: 67-72.

26 Wang Z, Lubin JH, Wang L, et al. Residential radon and lung cancer risk in a high-exposure area of Gansu Province, China. Am J Epidemiol 2002; 155: 554-564.

Patel JD. Lung cancer in women. J Clin Oncol 2005; 23: 3212-3218.

Tobacco Smoke and Involuntary Smoking. IARC Monogr Eval Carcinog Risks Hum 2004; 83: 1-1452.

Radon. In: Man-made Mineral Fibres and Radon. IARC Monogr Eval Carcinog Risks Hum 1988; 43: $173-259$.

Doll R, Peto R, Wheatley K, et al. Mortality in relation to smoking: 40 years' observations on male British doctors. BMJ 1994; 309: 901-911.

31 Husgafvel-Pursiainen K, Boffetta P, Kannio A, et al. p53 mutations and exposure to environmental tobacco smoke in a multicenter study on lung cancer. Cancer Res 2000; 60: 2906-2911.

32 Lee YJ, Cho BC, Jee SH, et al. Impact of environmental tobacco smoke on the incidence of mutations in epidermal growth factor receptor gene in never-smoker patients with non-small-cell lung cancer. J Clin Oncol 2010; 28: 487-492.

33 Pérez-Ríos M, Schiaffino A, López MJ, et al. Questionnaire-based second-hand smoke assessment in adults. Eur J Public Health 2013; 23: 763-767.

34 Laboratorio de Radón de Galicia. Mapas Medicións (Maps Measurements). http://www.usc.es/radongal/mapa_ med.html Date last accessed: October 13, 2013.

35 Barros-Dios JM, Barreiro MA, Ruano-Ravina A, et al. Exposure to residential radon and lung cancer in Spain: a population-based case-control study. Am J Epidemiol 2002; 156: 548-555. 